This is the peer reviewed version of the following article: Balibar, Etienne (2020) Ontological difference, anthropological difference, and equal liberty. European Journal of Philosophy, 28(1), pp. 3-14., which has been published in final form at https://doi.org/10.1111/ejop.12512 . This article may be used for non-commercial purposes in accordance with Wiley Terms and Conditions for Use of Self-Archived Versions 
Etienne Balibar

Université Paris-Ouest and Kingston University London

\title{
Ontological difference, anthropological difference, and equal liberty
}

The Mark Sacks Lecture 2018, June 1st, Birkbeck College, London

To be published in European Journal of Philosophy, 2020

version of the paper after peer review but before any

publisher branding or typesetting has been applied

\begin{abstract}
In this lecture, the author seeks to articulate in a systematic manner, although still tentative, the three ideas about which he has been developing his personal philosophy in the last period:

"Ontological difference", which after Heidegger and Derrida needs to become redefined in terms of a quasi-transcendental problematic of alterity; "anthropological difference", which covers the whole range of oppositions which at the same time are inseparable from a representation of the "human" and impossible to define as invariable binaries; "equal liberty", the combination of heterogeneous values which, since Ancient democracies and Modern republican insurrections, has installed the tension of emancipation at the heart of the political institution.
\end{abstract}

Ever since I received your invitation, I have thought that this would be a unique occasion to try and give some consistency to my work in progress on "anthropological differences", but I have also hesitated between two strategies: either I would cover, at least schematically, the complete range of questions which I believe are involved in this program where they must find a logical articulation, with the risk of remaining elusive and superficial on most of them; or I would select one dimension, and give a more thorough discussion of what it involves, at the risk of losing sight of the general intentions, which in my view are inextricably political and speculative. The result of my hesitations is a compromise, albeit leaning in the first direction. Hence my exuberant title: "Ontological difference, anthropological difference, and equal liberty". I will in 
fact follow the reversed order, which has a more reflexive orientation. My intention is to offer a trajectory that begins with politics and ends with metaphysics (or transcendental philosophy), with "anthropology" as a strategic mediation between the two, containing a reflection on what makes them indissociable - not in general, universally, but specifically and historically, because of their encounter around a disputed issue. Two expressions in the title: "equal liberty" (which I sometimes write in a single portmanteau form: equaliberty), and "anthropological difference", are not exactly my coinage (since they rely on existing semantics and philological traditions which are quite clear) but they have served now for some time as guiding notions for my work. ${ }^{1} \mathrm{I}$ am adding a third one, not the less resonant, "ontological difference", which I believe can be detached from the Heideggerian meaning but should also benefit from the stimulation that debates around Heidegger's philosophy have created. The result at which I am aiming is not a philosophy, much less a philosophical system, it is the continuation of a philosophical inquiry, whose implications I am trying to elucidate.

Here is the trajectory that I want to pursue. In the first part of the lecture, I return to the contradiction that affects political societies which, like ours, are founded on institutions granting equal liberty to their citizens, whereas they keep treating differences as instruments of exclusion, and above all, they justify exclusions in terms of differences. I suggest that this procedure creates a split (or antinomy) within the representation of nature, and what is "natural" in the human. In the second part, I specify which differences are strategic in producing political discriminations (or effects of non-recognition in the strong sense), and why their result is not so much a classification, or hierarchization of human types, as a permanent destabilization of dichotomies which are supposed to universally organize the relations among humans, or the relationship of the human species with itself. I discuss a formal criterion of anthropological differences in this sense. Finally, in the third part, I raise the question: which other concept of difference ought to be applied to the understanding of such anthropological differences, and how should it affect an ontology of relations - having in mind but leaving open the question of what political effects

\footnotetext{
${ }^{1}$ I refer in particular to Equaliberty. Political Essays, translated by James Ingram, Duke University Press, Durham 2014; Citizen Subject. Foundations for Philosophical Anthropology, translated by Steven Miller, Foreword by Emily Apter, Fordham University Press, New York 2016.
} 
such a new perspective (changer de différence, as my colleague and friend Catherine Malabou would say) would entail. ${ }^{2}$

Let's examine the first point. In a sense, of course, the contradiction between democratic ideas which are declared as their founding principles by most of our contemporary societies, and the heavy reality of discriminations, inequalities and exclusions that characterize our liberal "bourgeois" societies is not really mysterious, because it is quite simply a fact. Of course, the complete picture of discriminations is extremely complex because it evolves over time, and it refers to different aspects and fields of social life which are visible or not. They seem to arise from many different causes, which make them more or less objectionable, more or less acceptable in the eyes of those who, by contrast, appear privileged or immunized, or for the victims themselves. And, conversely, there are always citizens and groups of citizens who see it as a moral duty and a political urgency to gather forces against this or that form of discrimination, or at a more universal level against every discrimination, to struggle for "non-discrimination", which can receive different names. ${ }^{3}$ The question, however, is not only to describe facts, identify causes or choose between acceptation and revolt, it is to understand why, in modern societies as opposed to most "traditional" social orders which were hierarchic by definition, the distance between principles and facts appears as a contradiction, which consequently can be seen as unbearable, or as a pragmatic necessity. And, finally, it is the question of understanding how the unity of opposites, setting principles against facts, generates a discourse of politics in which emancipation and institution are permanently running behind their ideal unity.

My intention in discussing this traditional question is to push the contradiction to the extreme, in order to make visible the antinomy that it produces within liberal discourse itself, when the democratic principles and the generality of discriminations appear as opposite sides of the same universality, or we might even say, as the right side and the other side of a single universalistic discourse. In doing so, I try to avoid the weak representation of rights as forming the universal, whereas discriminations are only the particular: a representation which only too

\footnotetext{
${ }^{2}$ Catherine Malabou, Changer de différence, Paris, Editions Galilée 2009; English translation Changing Difference, translated by Carolyn Shread, Polity press, Cambridge 2011.

3 "Recognition" is certainly one of them: see the classical debate between Nancy Fraser and Axel Honneth: Redistribution or Recognition? A Political-Philosophical Exchange, New Edition, Verso, London-New York 2004. But equality is the most radical and all-encompassing one, with a dramatic history behind it.
} 
easily leads to the idea that the universal remains unaffected by its factual contradiction, or inversely that the elimination of the particular, practical discriminations is inevitable "in the long run". Let me also note in passing that an antinomy of the universal, constituting discourse itself, making universality conflictual, is not exactly the same idea as the well-known Marxist (or paraMarxist) idea, according to which universalistic principles have no other function than to cover and "mystify" the violent forms of domination that exist in the real. I believe that the antinomy arises in our case when both terms of the contradiction are referred to nature (or an equivalent of nature, producing an effect of "naturalization"), or when the unity of opposites takes the form of a dual meaning of "nature", creating an amphibology in the use and understanding of this category. This derives from the fact that, sometimes with a formal reference to God, sometimes in a completely secularized manner, the foundation of democratic principles is referred to natural right, natural law, the human essence or human nature, etc., whereas the discriminations are themselves supposed to express natural differences - which is the only condition under which they can appear as legitimate or non-arbitrary. However, this amphibology is not itself an obvious consequence of the meaning of "nature" as a moral or metaphysical category. Therefore, we must now make a detour.

I submit that the concentrated and idealized form in which democratic principles are presented (and explicitly declared) in the history of modern societies and political systems can be summarized in the statement that, in other places, I called the proposition of "equal liberty" or, in a single portmanteau word, "equaliberty". ${ }^{4}$ I did not claim that I had invented that idea, much the contrary, I derived it directly from the historical "declarations" or "bills" of rights issued by the English, American and French revolutions, whose formulations trace back to Ancient definitions of citizenship, and which are replicated until today in constitutional texts, such as the Universal Declaration of Human Rights, where emancipation and universal participation in the political institution are vindicated. By drawing attention to the logical structure of this statement, which is already implicitly based on a radical use of the negation, as an elenchus in the Aristotelian sense, asserting that there can exist no liberty without equality, and equality can exist only among free humans ("men", in the original formulations), I wanted to emphasize certain properties of the necessity that it expresses. First, there is the fact that the reciprocity of the two political

\footnotetext{
${ }^{4}$ See my book, quoted above: Equaliberty, collecting essays from 1989 to 2009.
} 
categories (no liberty without equality, no equality without liberty) does not suppress the tension between them. They remain a unity of opposites, for which a political articulation or synthesis 'which is always aleatory) must be found in the realm of politics. They call for praxis rather than obedience to a rule. Second, putting things in the terminology proposed by Rousseau in The Social Contract, this proposition immediately creates not a single, but a "double relationship" among the subjects who have become citizens in the democratic city: equality and liberty govern the horizontal relationship between the citizens, in civil or political matters, and they govern the vertical relationship between the citizens and the political authority, top down and bottom up, inasmuch as free citizens equally participate in the making of the law, and are equally subject to the rule of the law which they have authorized, without their essential liberty being diminished or suppressed by this obedience. ${ }^{5}$ As a consequence, citizens (or subjects of the democratic political society) are not only considered as free and equal, by means of some convention, but they are intrinsically free and, what seems semantically more difficult to formulate, they are intrinsically equal, inasmuch as they participate in the political society. Classical declarations, as we know, specify that this equality is to be considered "with respect to rights" (en droits), but there is and there can be no indication of a domain, a set of social relations that, by nature, eludes rights. The scope of rights is unlimited in principle. Reason why it needs not to be redefined when new rights are recognized (i.e. when existing discriminations are lifted): this is the intrinsic development of equal right, or equal liberty itself. ${ }^{6}$

A question however arises immediately. Clearly equal liberty can inspire constitutions, legislations, and practices, but as such it is an ideality, it names the essence of the political institution in radically universalist terms (in the sense of an intensive universality, one that institutes reciprocity wherever it is observed, or implemented). Shall we say that this ideality is also the dominant ideology of the bourgeois political societies, as Marx in particular seems to have implied when he wrote the famous sentences in Das Kapital: "Liberty, equality, property, and Bentham", in accordance with the juridical presuppositions of the circulation of commodities, form the "Eden of the Rights of Man"? ${ }^{7}$ I would say yes and no, because on the

\footnotetext{
${ }^{5}$ Jean-Jacques Rousseau : The Social Contract (1761), Book 1, chapter 7.

${ }^{6}$ See my description of the "trace of equaliberty", in E.B. Citizenship, Polity Press, 2015.

${ }^{7}$ See Karl Marx, Capital, Volume One, chapter 6: "This sphere that we are deserting, within whose boundaries the sale and purchase of labour-power goes on, is in fact a very Eden of the innate rights of man. There alone rule Freedom, Equality, Property and Bentham. Freedom, because both buyer and seller of a commodity, say of labour power, are constrained only by their own free will. They contract as free agents, and the agreement they come to, is
} 
one hand the dominant ideology that is established by liberalism (and this becomes even clearer with neo-liberalism) is not equal liberty but utilitarianism, and on the other hand equal liberty clearly figures the indelible trace, the discursive and institutional memory of the popular insurrections on which, directly or indirectly, the legitimacy of democratic institutions is founded. ${ }^{8}$ Utilitarianism (this is very clear in Herbert Spencer for example) contains a reference to the idea of "equal freedom", from which it derives the legitimate production of inequalities (especially economic inequalities, with their social consequences) by means of free competition a competition into which individuals are supposed to enter as equals and emerge widely different in wealth and power, following the rule of the survival of the fittest, which would be a natural law. ${ }^{9}$ Conversely, equal liberty as an absolute principle which, per se, can extend to any sphere of life, cannot but appear as a threat to any social and political order where inequalities are overwhelming, because it creates a symbolic link between the absolute character of insurrections at the origin of popular sovereignty, and the various movements challenging inequalities and discriminations in the present, rising against contemporary privileges and power relations. The many forms in which these two principles, partially incompatible, partially overlapping, are competing in modern history, account for the conflictual articulation of liberalism and democratism. They may also account for the existence of compromise formations, such as the widely accepted idea that meritocracy is an essential democratic institution, provided "equal opportunities" are granted to all individuals. ${ }^{10}$ But they stop short of explaining how, throughout

\footnotetext{
but the form in which they give legal expression to their common will. Equality, because each enters into relation with the other, as with a simple owner of commodities, and they exchange equivalent for equivalent. Property, because each disposes only of what is his own. And Bentham, because each looks only to himself. The only force that brings them together and puts them in relation with each other, is the selfishness, the gain and the private interests of each. Each looks to himself only, and no one troubles himself about the rest, and just because they do so, do they all, in accordance with the pre-established harmony of things, or under the auspices of an all-shrewd providence, work together to their mutual advantage, for the common weal and in the interest of all." In this description, it is to be remarked, the terms of classical declarations are mixed with a reference to the principles of utilitarianism, which is deeply ironic since Bentham himself was a fierce critic of the 1789 Declaration: see Jeremy Waldron, Nonsense upon stilts. Bentham, Burke and Marx on the Rights of Man, Methuen University Paperbacks, 1987.

${ }^{8}$ On this point, in his classical The Political Theory of Possessive Individualism (1961), C.B. MacPherson is ambiguous, to say the least. I find more support for my position in the scholarly work of Quentin Skinner (Cambridge University Press 1997) and Richard Ashcraft (Revolutionary Politics and Locke's "Two Treatises of Government", Princeton University Press 1986). My friend and colleague Frieder O. Wolf has found a significant reference to "equall liberty" in the Leveller's tract: see "The International Significance of the Levellers." In The Levellers, edited by Tony Benn and F. O. Wolf. Nottingham: Russell, 2000.

${ }^{9}$ See in particular The Principles of Ethics (1879_93), 2 vols, Indianapolis, Liberty Classics, 1978, where a permanent reference if made to "the principle of equal freedom".

${ }^{10}$ See Immanuel Wallerstein, "America and the World: Yesterday, Today, and Tomorrow" (1991) (reprinted as chapter 25 in The Essential Wallerstein, The New Press, New York 2000). In his now famous defense of equality
} 
the history of bourgeois societies, entire categories of subjects lack the opportunity to "compete" for power, citizen status, higher jobs, recognition, freedom of installation and movement, in other terms how there can exist a priori discriminations which appear legitimate (or which are proclaimed so, at least for a long period, despite the resistances and protests, while the democratic principles are reclaimed). Such discriminations must precede the recognition of rights, they must have their foundation outside the range of application of the proposition of equal liberty. In other terms - using the famous formula that Hannah Arendt coined, or perhaps borrowed, when she wanted to describe the situation of "stateless people" in a world of nationstates, which is now widely used by militant groups advocating the inclusion of refugees or migrants in the postnational societies - the discriminations must be rooted in the right to have rights itself. More precisely, they must be legitimated as a rightful denial of the right to have rights which has the same universality as the right to have rights itself, therefore can neutralize its effect. $^{11}$

This was the case, empirically, in a relatively recent past, for women, wage labourers, colonized people, and it remains the case today for strangers, migrants, children, and a variety of "deviant" people to whom I will return. But, again, how to legitimize the fact that the right to have rights, which is supposed to be inscribed in the very essence of the human, or in the tautological fact that all humans are humans, becomes negated or restricted for some of them? This can be done only if nature limits itself, or if it naturally sets apart certain natural beings. These beings are called "minorities", in the extensive or narrow juridical sense: but let's indicate in passing that, if each "minority" considered separately is perhaps smaller than the "majority" itself, the combination of all minorities is certainly vastly bigger than any count of the majority. The mark of a minority, or the intrinsic character, belonging at the same time, identically, to each individual and to the group, the class, the category into which she is incorporated is a natural difference, or a difference that has become naturalized (such as gender or race, or age, but also culture, ethnicity, nationality, particularly inasmuch as it forms a "property" that can be inherited,

against scholarly education, based on the $19^{\text {th }}$ century utopia of Joseph Jacotot, The Ignorant Schoolmaster (Stanford University Press, 1991), Jacques Rancière has argued for the exact opposite.

${ }^{11}$ In the vast discussion about this formula (to be found originally in Part II, chapter 5: "The Decline of the NationState and the End of the Rights of Man" of The origins of Totalitarianism, 1951), I single out the interpretation proposed by Bonnie Honig, Emergency Politics. Paradox, Law, Democracy (Princeton University Press, 2009). See a recent update of controversies by Stephanie DeGooyer, Alastair Hunt, Lida Maxwell, Samuel Moyn, Astra Taylor; The Right to Have Rights, Verso, London 2018. 
and becomes part of a genealogy). ${ }^{12}$ A natural difference is one that individuals cannot not possess, or cannot deny having, by virtue of their belonging to a class constitutive of the human. But, in a typical ideological circle, it is only for individuals belonging to "minorities" in the qualitative sense that differences become instruments of absolute identifications or cannot be just neutralized through the access to rights. Conversely, whoever has access to rights merely qua human is one for whom the natural differences are neutralized, or most likely one whose difference is not naturalized and essentialized, so that he can enter the public realm, as a pure representative of the "human". ${ }^{13}$ With this splitting of the articulation between nature and the institution, the universality of the proposition of equal liberty remains valid, or even it is validated through its own exceptions and counterfactuals.

With this reconstruction of the idea of natural differences, or better said the naturalization of differences, we have entered the discussion of "anthropological differences" proper, which is my second point. When they are seen from a historical perspective, natural differences which have the capacity to limit the right to have rights, or create legitimate exceptions to its validity, appear as a construct that can be also deconstructed. Or better said, it is because and when they are deconstructed, usually as a result of protracted struggles and "civil wars" within the polity, that they appear retrospectively as constructs, whose historical and political character becomes manifest. This is today increasingly the case for the gender difference or even the racial difference, but it is far from being the case for the age difference (between adults and children) and for "pathological" differences of various kinds (which are now in the course of being forcefully re-naturalized when they had been critically deconstructed, through the invasion of psychiatry and medicine by genetic and genomic technologies and ideologies). Until a "naturalized difference" has been deconstructed, it is always difficult, if not impossible, to argue that it is a political instrument of discrimination that ought to be lifted in accordance with the universality of the principle of equaliberty. The evidence of naturality is therefore a discursive

\footnotetext{
${ }^{12}$ On the importance of this "genealogical scheme", see my essay : "Election/Sélection", in Cahier de l'Herne Derrida, sous la direction de Marie-Louise Mallet et Ginette Michaud, Editions de l'Herne, Paris, 2004.

${ }^{13}$ In French-speaking critical theory, the work of Colette Guillaumin has been of particular importance in my reflection (see her 1992 book: Sexe, race et pratique du pouvoir, éd. Côté Femmes. Réédition éd. IXe 2016).
} 
formation that calls for analysis and is never simple. It is this complexity that I want now to briefly examine.

I begin with two correlative remarks, which introduce the important idea of the relationship between universality and violence. The first is to say that, in my opinion, not every "difference" that affects human beings and can become invested with power relations must be counted as an "anthropological difference" in the strong sense. There are limit-cases, of course, which are overdetermined because they change meaning over time, or the hierarchies and exclusions within the bourgeois society include many legacies from the past which can become reactivated or not : I am thinking of religious differences, which have many analogies with national and ethnic differences, or the difference between sedentary and nomadic humans, which was elevated by Deleuze and Guattari (in A Thousand Plateaux) to the status of a foundation for the emergence of "civilization" and its articulation with the transformation of war into a statefunction, and is now producing a dramatic rift in the geopolitical condition of mankind. However, it seems to me that, keeping in mind the idea of a negation of equal liberty that operates from inside, or affects the universality of the principle itself, we must focus on differences that are universal themselves, or that must be universalized to translate into institutions, even if we see them as historically or culturally variable in their definition. ${ }^{14}$ The examples are plain: there is no way of representing the human without a sexual difference, although we can dispute whether the "feminine" and the "masculine" are stable essences (mankind is a composition of men and women); there is no way of representing the human without a difference between the normal and the pathological (mankind is a composition of sick and healthy people) although such notions as "health" and "illness" are decidedly variable, as is their interference with "deviancy", "criminality", etc. We observe immediately that such differences are always associated with strong power relations, therefore with a suppression of resistances or the existence of structural violence. Thus, we come to the idea that an anthropological difference in the strong sense is a difference whose naturalization universally creates a relationship of domination or exclusion (both of them, of course, in the case of sexual difference, and also others), which confers upon

\footnotetext{
${ }^{14}$ We may observe that this is similar to the function attributed by Claude Levi-Strauss to the "prohibition of incest", which according to him inaugurates "culture" as opposed to "nature" (meaning in practice humanity opposed to animality) or makes culture a "second nature". However, whereas the Levi-Straussian criterion is transcendental, my criterion of the universal negation of universality (or the antinomy of the universal) is immanent (quasitranscendental).
} 
universality itself an antinomic character. The resolution of the antinomy typically produces a political double bind that, as we all know, forms the permanent dilemma of movements seeking the emancipation of "minorities", which should choose between abolishing the discrimination, or the power relation, at the expense of the difference itself which could be violently neutralized, or vindicate and valorize the difference at the risk of reproducing the roots of the domination indefinitely. ${ }^{15}$

Which leads to my second remark: violence is really "doubling" every anthropological difference in the strong sense, and it is maximized by the conflation of nature and construct, or their permanent exchanges. ${ }^{16}$ However, this violence stretches from one extreme to the other: it includes the everyday distribution of individuals among different activities and functions so "customary" that power barely needs to become legally asserted; or the violence is its consequence rather than its cause, it betrays the intrinsic excess of any vested power relation, as well as spectacular processes of elimination of "internal enemies" and "aliens". ${ }^{17}$ But we also know that these seemingly incompatible forms of violence are exchanging places when circumstances permit. A new indication that, with the consideration of anthropological differences, we are not in the realm of stability and calm distributions of human beings and social roles into classes, but in the realm of intrinsic instability. It remains now to incorporate the instability into the very definition itself, making it a constitutive feature.

Before I come to this new logical moment, however, I must devote some considerations to the difficult issue of the multiplicity of anthropological differences and the obstacles to their classification in a single typology. I have referred allusively to various relations which illustrate in the first place the idea of a universal opposition that cuts across the human or creates a symbolic line of demarcation within the totality of mankind which can become invoked for domination and discrimination, also opening the possibility of a "reconciliation" of mankind with itself, albeit usually at the cost of power struggle and violence. But I have only proposed scattered examples, nothing like a list of major anthropological differences, as I did in other

\footnotetext{
${ }^{15}$ I have relied on the discourses of Fanon and Wollstonecraft on race and sex to discuss this double bind in my Citizen Subject (already quoted), conclusion: "Bourgeois universality and anthropological differences".

16 (for which Bertrand Ogilvie reserves the category "second nature")

${ }^{17}$ See my analysis of "ultra-objective" an "ultra-subjective" violence, in E.B. Violence and Civility, On the Limits of Political Philosophy, translated by G.M. Goshgarian, Columbia University Press 2016.
} 
places albeit always indicating that such a list had a mere preliminary function and could only lead to identifying new aporias.

There are several reasons for that, of which again I will retain two, taking us from epistemology to ethics. First reason: the list of anthropological differences must remain open, therefore their definition arising from comparison must also remain relatively indeterminate, because we cannot deduce them from a positive anthropology, which would register "facts". The discriminations based on anthropological differences, contradicting the principle of equal liberty, are facts, but the names and subjects of these differences are interpretations, they arise in a retrospective manner from the fact that the discriminations and forms of dominations have become challenged, in such a manner that the universal validity of their anthropological foundations and references have become questioned and appeared fragile, or that they have created uneasiness in society, both in terms of their objective determination and in terms of the insecurity for individuals who refuse to identify with either the places or the functions of the difference. To be or not to be a man or a woman with the recognized attributes of masculinity and femininity, to be or not to be a healthy person or a moral or physical deviant, again according to certain norms that are at the same time general and arbitrary, such are the experiences which impose the consciousness of the differences singularly rather than collectively (or collectively only in the second place, in the framework of a participation to a movement, therefore through the submission to other ideological norms). At this point we meet again with the aporias of a classification that is enforced by society in a "naturalized" manner but could be entirely challenged only from the imaginary vantage point of a position that is located outside the society itself. I am not saying that this never takes place, I am just underlining the fact that it is not "objective" in the positivist sense of the term, therefore it remains subject to the vacillations and conflicts of history.

But there is a second reason which leads to withholding, as it were, the enumeration of anthropological differences, or the construction of a picture of the differences which would also represent, a contrario, a kind of picture of the human condition through its divisions, or seen from its other side (what is the human, if not this form of life, or community that is sexually divided, pathologically divided, intellectually divided, divided by age into children and adults, educators and educated, morally divided into honest persons and criminals, etc.?). What retains 
us from going all the way along this line is precisely the fact that each difference has a singularity that risks being blurred in the enumeration and the comparison. It is especially perilous to define the dominant feature of a specific difference through its analogy with another one, as we do if we push the idea of "naturalization" to the point where it becomes a formal key to the understanding of race in terms of gender, and gender in terms of race, whereas the difficulty comes from the fact that they are never separated, but never complementary. There is a general problem, but no general concept of anthropological differences.

This difficulty, in today's political language, has a specific name: it is called "intersectionality". I am not challenging that name, because I know that it indicates a problem, to be discussed politically as well as intellectually, rather than a solution, or a single methodology. ${ }^{18}$ What I am tempted to say, which reflects what I perceive of the ambivalent uses of the category in contemporary debates, is that the addition or intersection of differences which make it possible to compare the status of several minorities, essentially comes from the fact that, in a political society like ours, there exists tendentially a representation of the hypernormal, which would arise from the combination in one single person, or one personal type, of all the "dominant" functions and qualities that result from subordinating others. Therefore, it is a negative reference for the virtual community of resistance of the discriminated others, the figure of their common enemy or master. ${ }^{19}$ It is in fact represented through the accumulation of negations of the "negative" qualities involved in the use of anthropological differences as a means of discrimination, which however produces only an imaginary type, even a kind of "human monster". We are reminded of the amazing type - at the same time completely ordinary and completely surrealistic itself which Erving Goffman had called the "normal deviant", identified in such terms with the typical American citizen: "For example, in an important sense there is only one complete unblushing

\footnotetext{
${ }^{18}$ It is important, I believe, that the classical (if not the first) problematization of intersectionality by Kimberle Crenshaw, aiming at describing and opposing the combination of racism and sexism, which is a positive reality, nevertheless uses the trope (or logical form) of double/simultaneous negation: the experience of a black woman is neither to be understood in generic terms of "being black" nor in generic terms of "being a woman" (see Kimberle Crenshaw, Mapping the Margins: Intersectionality, Identity Politics, and Violence against Women of Color, 43 Stanford Law Review 1241 (1991). For readers of French I recommend the critical synthesis by Hourya Bentouhami, Race, cultures, identités : une approche féministe et décoloniale, Paris : PUF 2015.

${ }^{19}$ In his Politics (especially Books 1 and 3), Aristotle constructed a logical system of the oppositions which differentiate the human (Anthropos) both politically and ontologically by correlating the autonomy of the citizen and the dependency of three types of "subalterns" in the household (oikos): women, children, slaves. Their respective "essences" are thus mutually (and relationally) defined. We have here a negative reiteration of this pattern in modern conditions.
} 
male in America: a young, married, white, urban, Northern, heterosexual, Protestant father of college education, fully employed, of good complexion, weight, and height, and a recent record in sports. Every American male tends to look out upon the world from this perspective, this constituting one sense in which one can speak of a common value system in America". ${ }^{20}$ It would seem that the comparison and, a fortiori, the combination of anthropological differences into a single model only produces an ironic double of their own violence: not a negative picture of the human when observed from its reverse side, as it were, but rather a picture of the negativity of the human, in its irreducible multiplicity.

This negativity, however, can also be considered philosophically as key to the understanding of the function of anthropological differences, provided - while remaining at the level of a formal, open enumeration, we understand it as a negativity which is reflected by each difference within itself, in a singular manner. In previous essays I proposed a formal criterion to address this form of negative reflexivity, which I want to briefly repeat here. It can be considered a complication of the first criterion that I used a moment ago, the criterion of the universality of the differences which "contradict" the universality of the human essence, or transform it into a unity of opposites. We are now moving from universality to singularity without losing the first determination. What I have in mind is the fact that, each time in a specific manner, anthropological differences confront us with a double impossibility: the impossibility of erasure, eliminating the difference either symbolically or practically in the organization of life and the working of institutions, as well as the impossibility of definition, assigning a stable and identical place and design to the "line of demarcation" between antithetic poles of the human. And let us remember here that there is, or can be, as much violence in the project of neutralizing anthropological differences as there is in the project of deciding forever and for all what constitutes the difference, which marks of difference are to be upheld, and which are to become silenced or suppressed.

This idea was suggested to me by the reading of Foucault, especially his work on Abnormals and the history of the penitentiary system in modern Europe, where he shows that the distinction of criminals and innocents before the tribunals has been overdetermined by the

\footnotetext{
${ }^{20}$ See Goffman's celebrated essay from 1963, Stigma: Notes on the Management of Spoiled identity, Simon and Shuster, New York (reprinted Touchstone Books, 1986, p. 153).
} 
necessity and impossibility of strictly demarcating madness and criminality, which generates the endless institutional competition of the judiciary and the medical practices - the conflict of the faculties, in Kantian terms. ${ }^{21}$ From there I moved to the idea that, in a similar manner albeit with a completely different content, the impossibility of providing a "definition" of what distinguishes femininity from masculinity is verified by the impossibility of attributing specific forms of sexuality and sexual behavior to each gender, while it is also this social and moral imperative of distinction that imposes a non-neutralization of the sexual difference, without which "heteronormativity" would be unthinkable. This is really the core of every process of "identification" of self and its typical "uneasiness", since it is never one side only that is internalized, but the double bind itself, at the cost of more or less unconscious repression. ${ }^{22}$ And perhaps we retrieve the same kind of double bind, although again with a completely different content, in the case of the difference between childhood and adulthood, which I have a tendency now to view as the most enigmatic of all despite its apparent obviousness. In modern societies, a simple binarism has replaced here the complex chronologies and hierarchies of age and maturation that existed in all traditional societies, allowing it to grant functions and places to all humans according to their age and gender. There are of course all sorts of names for the “intermediary" status (usually seen as a "transition" phase), such as "teenager" (or simply "teen") in English, but the binary distinction of child and adult remains prevalent in our societies, where it tendentially coincides with the moment of access to legal independence and active citizenship, but is also overdetermined by the uncertain question of the sexual responsibility (which periodically becomes a burning social issue, in relation to matters of interdiction of and protection from violence in sexuality). ${ }^{23}$ To which we may add the coincidence with a distinction between the functions of educated and educator, which has a completely different logic and is not

\footnotetext{
${ }^{21}$ See Michel Foucault, Abnormal: Lectures at the Collège de France, 1974-1975, Picador; Reprint edition (September 1, 2004). Also, the 1977 Lecture entitled 'About the Concept of the 'Dangerous Individual' in 19th Century Legal Psychiatry'. It was published first in English in International Journal of Law and Psychiatry, Vol 1 No 1, pp, 1-18. It was reprinted in Foucault, Politics, Philosophy, Culture and again in Foucault, Essential Works Vol III.

${ }^{22}$ I believed to be able to trace back this specific figure of "uneasiness" (which we are accustomed to understanding in Freudian terms) to the very origin of the word in the work of John Locke: see my essay Identity and Difference. John Locke and the Invention of Consciousness (revised English edition, with an Introduction by Stella Sandford), Verso 2013.

${ }^{23}$ A new recent French legislation (2018) decided that individuals of either gender under the age of 15 who have sexual relations with adults (= above 18 years) must be presumed not to consent, therefore being "raped", which shows clearly the uncertainty of the definition of who is an adult and who is not. The age is different (above or under) in similar legislations of other countries.
} 
intrinsically associated with age. ${ }^{24}$ This overdetermination produces an increased social pressure to maintain, and interiorize, the idea that adults and children are naturally different, but also, they make the point of transition multiple and permanently shifting, fostering conflicts, even violence. We have thus three illustrations, with specific historical and moral implications, of the validity of this negative criterion, which is also an index of negativity: anthropological differences which are strong enough to become universalized, are not definable, either objectively or subjectively, but they are also not dispensable.

\footnotetext{
24 The very name "pedagogy" (whose etymology comes from ancient Greek pais, usually calling a boy or male child, therefore "the conduct of boys") and its preservation from one time to another, calls for a critical genealogy, where, in particular, the confusion of learning and raising or bringing up would be analyzed.
} 
In my third part, I want to confer upon this negativity an ontological meaning, which is also a way of suggesting that only a movement towards ontological considerations does eliminate the appearance of sophistic multiplications of aporias in the previous descriptions. As we know, negation and negativity are polysemic categories - there is even in Kant's Critique of Pure Reason a famous table of the meanings of "nothingness" - which form privileged indicators of the choices that an ontological discourse must face, therefore also a guiding thread for the articulation of ontology with empirical determinations. In Heideggerian terms, this would be a question of the difference between Being as Sein, and being as das Seiende, which he does not articulate positively - in terms of the "participation" of multiple beings (or modalities of being) in the unity or universality of Being as such (a supreme "genre" as it were), but negatively, in terms of the "withdrawal" or "absence" of Being from its own manifestations, the diverse forms of beings or things of our experience. ${ }^{25}$ Except that here, in our reflection on the ontological character of the anthropological differences, what we need by definition is not a discourse on "being" and "things" (or the essence of things): it is a discourse on relations as such - the modes of "relating to", and their intrinsic indeterminacy. In the following sketch, I will try and combine negativity, relationality, and difference in such a way as to conceptually determine this practical indeterminacy. ${ }^{26}$

My first point begins once again with a negation. It relates to the fact that, although anthropological differences, especially in their institutional - therefore legal - realization, continuously serve to identify individuals, or to endow them in their own eyes and in the eyes of

\footnotetext{
${ }^{25}$ The original definitions of "ontological difference" (which is only latent in Being and Time, where "ontology" also retains a more traditional sense) are to be found in Identity and Difference (Identität und Differenz, 1957, containing the two essays on "The principle of identity" and "The onto-theological constitution of metaphysics") and Introduction to Metaphysics (Einführung in die Metaphysik, 1935, published with revision in 1953). Among the many commentaries, I rely in particular on Françoise Dastur, Philosophie et Différence, Editions de la Transparence, 2004, who traces a complete genealogy to the pre-Socratic thinkers and particularly discusses the opposition to Hegel.

${ }^{26}$ Much of what I know about the ontological implications of a logical concept of "relation" comes from Hidé Ishiguro's discussion of Russell's distinction between "internal" and "external" relations in her book on Leibniz's philosophy of logic and language ( $2^{\text {nd }}$ edition, Cambridge University Press 1990). On the neo-platonic understanding of relations as the site of transcendence within immanence, which is so important for contemporary discourses on "alterity", comes from, I find the whole work of Stanislas Breton uniquely illuminating (see Matière et dispersion, Jérôme Millon, Grenoble 1993). On relation as "interruption" according to Maurice Blanchot, equally influential on Foucault and Derrida, see "Le rapport du troisième genre" in L'entretien infini (Gallimard 1969) (English translation and introduction by Susan Hanson, The Infinite Conversation, The University of Minnesota Press 1993).
} 
others with properties and qualities which confer "identities" upon them, collectively or separately, the difference as such is not based on individuation and individuality. Rather, it is transindividual and escaping the reach of the individual. Individuals are named and categorized as "men”, “women”, “children”, “whites”, “blacks”, "brown”, "rational”, "lunatic”, "honest”, "criminal", etc., but these do not name classes to which they can be assigned by means of such denominations, which simply means that they are identified through, or excluded from certain capabilities. Or, if you prefer, such assignations represent a violent forcing of stable identities and clean boundaries where, in practice, there is only vacillation and continuous displacement. We are thus led to abandoning the primacy of individuation and the whole semantic of "properties" (or "attributes") assigned to subjects in the ontological sense of the term, with its classical dilemmas of contingency and necessity, and turn towards the other possibility, which is a relational ontology : an ontology in which it is the relation itself that has to be endowed with a certain modality of being - or perhaps better, a certain modality of changing, becoming and oscillating.

But this only displaces the difficulty: what is a relation, or, rather, how do we describe relationality, i.e. the active, productive element of "relating to" - which the Greek name that we translate as "relation" in Aristotle : to pros ti, beautifully indicates (even better than its Latin equivalent: esse $a d$ ), because it suggests a "moving towards" which in itself always remains to be determined, and for that reason could also point at an essential indeterminacy. ${ }^{27}$ If we stick to that idea, having the conflictual realization of anthropological differences in mind, we see that not every way of conceptualizing relations can do the job. This cannot be done simply by importing the standard logical concept of a relation, because this concept merely represents a formal reversal with respect to the logic of properties, attribution and predication, where it is the abstract form of the relation that precedes the identification of the terms which, when they "satisfy" the condition stated in the relations, will be said to be or not to be related, or relating to one another - with no third possibility (of two given terms, A and B, we can say that they are related to one another in the modality $R$ if and only if $\mathrm{A} R \mathrm{~B}$ is true...). If they differ, this will be simply because the relation is constructed as a dissymmetry. We know that structural anthropology has made

\footnotetext{
${ }^{27}$ The reverse idea, which gives rise to the philosophical discourse of intentionality, but also can lead to the Spinozian notion of transindividuality, is the idea of "being open to" in the sense of "affecting and being affected by". See my essay "Philosophies of the Transindividual: Spinoza, Marx, Freud", forthcoming in the special issue of The Australasian Philosophical Review on transindividuality (2018 or 2019).
} 
extensive use of this logical model, but it goes hand in hand with the fact that it tends to reify the anthropological differences, attributing them or some of them (particularly those which relate to kinship) a defining function for the social, or the cultural order. ${ }^{28}$ For analogous reasons, we can also not directly borrow a Marxian dialectical model of the "social relation", because, although the Marxian concept of social relation (in production and elsewhere) crucially unsettles the stability of the terms (or the "classes") subsumed under its determination, by stating that their essential mode of relationality is conflict, or "struggle", through which they transform each other, therefore become transformed themselves, the Marxian model nevertheless reifies or fixes the antagonism as such. It makes it an invariant of the conflict itself, thus inevitably conferring upon the relations the properties of a "substance", or a being of beings, a founding hypostasis for the lived experiences which derive from the structural causality of the social relation. ${ }^{29}$ What we seem to need, in order to conceptualize the modality of "relations" involved in the description of anthropological differences which indetermine (or un-determine) the very distinctions that they establish, therefore, is not only an idea of relation that is immanent to the variations that it produces, but also an idea of relation that involves its own negation, or limitation: unbinding as it binds, un-differentiating as it differentiates, involving irreducible heterogeneity where it established homogeneity... ${ }^{30} \mathrm{I}$ am aware that we find ourselves here on the verge of sophistry, but this is the kind of sophistry that arises from the manifestations of the thing itself, that philosophy has always tried to transform into a dialectical idea.

There are different ways in fact of achieving that, which have intrinsic relations with a reflection on anthropological differences that I find inspiring. Leaving aside, for today, certain remarkable developments in Kant's juridical and anthropological definitions of so-called "personal-real relations", where the symmetry of relations becomes affected by an intrinsic

\footnotetext{
${ }^{28}$ See Claude Levi-Strauss, Elementary Structures of Kinship (Les structures élémentaires de la parenté, 1949), Beacon Press 1969, with the mathematical formalization of the relations by André Weil in the appendix. However, in a later essay (now reprinted in Structural anthropology, The Penguin Press., 1968) "Structural analysis in linguistics and anthropology", he modifies the "necessity" of kinship relations with an oscillation between the determinacy of nominations and the indeterminacy of attitudes.

${ }^{29}$ On the problem of a "relational ontology" in Marx, see my book The Philosophy of Marx, Updated New Edition, Verso 2017.

${ }^{30}$ See Blanchot, "Le rapport du troisième genre » (« The relation of the third kind - Man without horizon"), in The Infinite Conversation, quoted above.
} 
heterogeneity, ${ }^{31}$ I will particularly mention Derrida's deconstruction of the Heideggerian notion of the "ontological difference" by means of its contamination with sexual difference, as it is presented in the essay called Geschlecht (itself a supremely ambiguous name in German, whose English or French "equivalents" range from genre to race to sex to gender...). ${ }^{32}$ In a remarkable commentary of this essay and the problems it raises from a "feminist" point of view, Elizabeth Grosz has defined the result produced in the text as "ontological equivocation", while particularly insisting on the "trouble" that Derrida produces in the association of the idea of sexual difference and differences with binary oppositions, or binarism in general as a metaphysical presupposition of the common representation of a "relation", or "relating to" in general. ${ }^{33}$ On my part, I would say that Derrida at the same time introduces relationality and difference where they had been conspicuously neutralized and reduced by Heidegger (through an application of his notion of ontological difference to a generic Dasein), and he destabilizes the representation of a "relation" that is based on the opposition of antithetic predicates, such as masculinity and femininity, by identifying the "thing" at stake in a sexual relation (or if you like its "object", in the rather unusual meaning adopted by Freud) as neither homogeneous nor heterogeneous, neither self nor other. ${ }^{34}$ Which seems to be a fairly convincing via negativa towards the idea of radical alterity.

But it also makes sense to compare this suggestion with an interpretation of what, in an earlier essay, Derrida introduced as the quasi-transcendental concept of differance written with $a$ instead of $e$ (fortunately we have the same possibility of variation in English and in French). This is because the idea of difference where, following a standard grammatical pattern in French (not fully retrieved in English) the accent is put on movement, on temporalization and becoming instead of the result or final determination, can be interpreted as a suspension of the determination of differences, a glimpse at the moment when differences are nascent but not fixed - not even in the form of an antagonism. But it can also, more interestingly for our purpose, be

\footnotetext{
${ }^{31}$ I am referring to the section in Kant's Philosophy of Law ("Metaphysical Principles of the Science of Right", 1795) on "Personal Right of a Real Kind", where he includes all the fundamental relations of the "domestic" sphere: marriage, parenthood, service).

32 Jacques Derrida; "Geschlecht. Sexual Difference, Ontological Difference “, Trans. R. Berezdivin, Research in Phenomenology 13 (1983), 65-83.

${ }^{33}$ See Elizabeth Grosz: "Ontology and Equivocation: Derrida's politics of Sexual Difference", diacritics, 25-2, summer 1995, 115-24. To "trouble" binarism is not the same as including "binary relations" in the broader logical concept of "n-predicates" (or predicates with more than 2 arguments).

${ }^{34}$ This is the « object » in the Freudian sense ("object-relations" or libidinal objects). But this meaning is already there, at least grammatically, in Descartes and other classical theorists of the "passions": see my essay "Lovence in Rousseau", in Citizen Subject, quoted above.
} 
interpreted as idea of a difference that is always already affected by another difference, a difference within difference as it were, or a difference which will always become different of itself, differing from the difference that it is. This is, I believe, if I understand it well, a very remarkable approximation of the paradoxical properties of anthropological differences as I tried to describe them very generally. It would have logical but also ethical and political consequences, because it complicates, but does not suppress the representation of a struggle or a resistance against discriminations based on differences, in a way that is bound to challenge not only the identification of the other, but also the identification of oneself. Pushing the idea one step further, and also returning to the general question of how to think, or conceptualize, a relation that establishes differences in a necessary manner that is also essentially indeterminate, I would say that we are led to the imagination of a difference whose "relational" modality is negating "identity" not only externally (in its applications), but also internally (in its concept), thus radically avoiding the implicit transformation of difference into another instantiation of the same, or sameness.

Through these successive steps, we have been moving from an ontology of relations to an ontology of otherness as a condition for relating or interrelating, to an ontology of differences as continuous alteration of oneself and others. It would remain to discuss whether, in three developments focusing respectively on politics (equaliberty), anthropology (differences), and ontology (relations), we have just repeated the same idea in three different codes or added something to our understanding of the tasks of philosophy. There is no more room for that today, but perhaps it is better to leave the question open for discussion and reflection. 